\title{
WORKING CAPITAL MANAGEMENT DAN FIRM PROFITABILITY PERUSAHAAN SEKTOR MANUFAKTUR DI BURSA EFEK INDONESIA DAN BURSA EFEK FILIPINA PERIODE 2014-2018
}

\author{
Ricky Adiyanto \\ Faculty of Business and Economics, Universitas Surabaya, Indonesia \\ ricky.adiyanto1998@gmail.com \\ Werner R. Murhadi \\ Faculty of Business and Economics, Universitas Surabaya, Indonesia \\ werner@staff.ubaya.ac.id \\ Liliana Inggrit Wijaya \\ Faculty of Business and Economics, Universitas Surabaya, Indonesia \\ liliana@staff.ubaya.ac.id
}

\begin{abstract}
This study aims to analyze the effect of working capital management on the profitability of companies in Indonesia and Philippines. This study uses secondary data from companies listed in Indonesia Stock Exchange and Philippines Stock Exchange in the 2014-2018 period. The sample used in this study includes manufacturing sector companies listed in Indonesia Stock Exchange and Philippines Stock Exchange in that period. This research uses multiple linear regression method. Working capital is measured using cash conversion cycle, accounts receivable conversion period, inventories conversion period, and accounts payable deferral period. The results of the Indonesian sample show that the cash conversion cycle and its components, namely the accounts receivable conversion period, the inventories conversion period, and the accounts payable deferral period have a significant positive effect on firm profitability. For the Philippine sample, the result of the study show that the cash conversion cycle and its components does not have a significant effect on firm profitability.

Keywords: cash conversion cycle, accounts receivable conversion period, inventories conversion period, accounts payable deferral period
\end{abstract}

\section{LATAR BELAKANG}

Modal kerja menjadi kebutuhan perusahaan dalam membiayai setiap kegiatan operasinya agar usaha berjalan lancar sesuai dengan rencana yang dibuat perusahaan. modal kerja adalah jumlah keseluruhan dana yang tertanam dalam aktiva lancar yang terdiri dari kas, surat berharga, piutang dan persediaan, dimana unsur-unsur aktiva lancar tersebut dimaksudkan sebagai aktiva yang secara normal dapat berubah menjadi kas dalam jangka waktu yang relatif pendek atau kurang dari satu tahun 
(Syaifuddin, 2008). Modal kerja juga menjadi sumber kehidupan bagi setiap perusahaan (Padachi, 2006 dalam Afrifa \& Padachi, 2016) Oleh karena itu, modal kerja bisa menjadi ukuran efisiensi serta kondisi keuangan perusahaan. Jika perusahaan memiliki modal kerja yang cukup, perusahaan tentu dapat beroperasi dengan efisien dan tidak mengalami kendala dalam keuangannya.

Cash flow yang stabil sangat penting untuk mempertahankan bisnis, dan modal kerja yang cukup akan memaksimalkan profitabilitas perusahaan (Tran et al., 2017). Tahir \& Anuar (2016) dalam Altaf \& Shah (2018) berpendapat bahwa modal kerja dianggap sebagai kehidupan untuk setiap kegiatan ekonomi yang memainkan peran penting dalam manajemen perusahaan. Agar perusahaan memiliki modal kerja yang cukup untuk membiayai aktivitas usahanya, perusahaan dapat melakukan manajemen modal kerja. Manajemen modal kerja merupakan bidang keuangan yang signifikan; efisiensi manajemen modal kerja dapat memberikan dampak yang signifikan bagi profitabilitas dan bisnis (Deloof, 2003; Shin \& Soenen, 1998 dalam Tran et al., 2017). Smith (1980) dalam Altaf \& Shah (2018) mengatakan manajemen modal kerja sangat penting karena mempengaruhi profitabilitas dan risiko perusahaan, dan juga nilai perusahaan. Manajemen modal kerja juga penting bagi perusahaan karena melibatkan trade-off antara risiko dan profitabilitas (Smith, 1980; Tauringana \& Afrifa, 2013 dalam Afrifa \& Padachi, 2016). Deloof (2003) dalam Murhadi (2013) mengatakan pengelolaan modal kerja memiliki dampak signifikan pada kinerja keuangan khususnya profitabilitas perusahaan. Dengan manajemen modal kerja yang efektif dan efisien, perusahaan dapat mengoptimalkan pendanaan internal dan dapat meminimalisir ketergantungan terhadap pendanaan eksternal.

Pais \& Gama (2015) melakukan penelitian tentang working capital management dan profitability Usaha Kecil dan Menengah (UKM) di Portugal. Penelitian ini bertujuan untuk menunjukkan bukti empiris tentang efek working capital management pada profitabilitas UKM menggunakan sampel 6.063 UKM di Portugal periode 2002-2009. Hasil penelitian menunjukkan bahwa Cash Conversion Cycle (CCC), Accounts Receivable Conversion Period (ACP), Inventories Conversion Period (ICP), dan Accounts Payable Deferral Period (APP), dan leverage berpengaruh negatif signifikan terhadap firm profitability. Sedangkan firm size, GDP Growth (GDPGR), Sales Growth (SGROW), Current Assets Ratio (CAR), dan Current Liabilities Ratio (CLR) berpengaruh positif signifikan terhadap firm profitability.

Penelitian lain dilakukan oleh Tran, Abbott dan Yap (2017) yang meneliti pengaruh working capital management terhadap profitabilitas perusahaan UKM di Vietnam menggunakan sampel 200 UKM manufaktur yang terdaftar di HSE (Ho chi minh Stock Exchange). Hasil penelitian menunjukkan bahwa CCC, ACP, ICP, APP, dan leverage berpengaruh negatif signifikan terhadap firm profitability. Firm size berpengaruh positif insignifikan terhadap firm profitability, sedangkan SGROW berpengaruh positif signifikan terhadap firm profitability. Sedangkan Murhadi (2013) melakukan penelitian tentang manajemen modal kerja dan profitabilitas di Bursa Efek Indonesia menggunakan sampel perusahaan yang terdaftar dalam indeks LQ-45 
periode 2008-2011. Hasil penelitian menunjukkan bahwa CCC, ACP, dan firm size tidak memiliki pengaruh terhadap firm profitability. ICP dan APP berpengaruh positif signifikan terhadap firm profitability. Sedangkan leverage berpengaruh negatif signifikan terhadap firm profitability.

Modal kerja berfungsi sebagai kekuatan perusahaan untuk mendanai kegiatan operasi perusahaan sehari-harinya, selain menjamin kebutuhan jangka pendek perusahaan. Pengelolaan modal kerja secara efisien memainkan peran penting bagi keseluruhan strategi perusahaan yang bertujuan untuk menciptakan nilai bagi pemegang saham (Murhadi, 2013). Pengelolaan modal kerja yang efektif dalam suatu perusahaan dapat dilihat dari indikator siklus konversi kas-nya (Deloof, 2003; Gill, et al., 2010; dan Enqvist, et al., 2012 dalam Murhadi, 2013). Dengan manajemen modal kerja yang efisien, perusahaan dapat mengurangi risiko terjadinya financial distress dan dapat meningkatkan profitabilitas perusahaan. Perusahaan dengan siklus konversi kas yang pendek mengindikasikan perusahaan mampu mengumpulkan piutangpiutangnya dengan cepat dan membayar supplier lebih lambat namun tetap menjaga kredibilitas perusahaan (Murhadi, 2013). Semakin pendek siklus konversi kas, dapat meningkatkan profitabilitas perusahaan karena perusahaan mampu menghasilkan pendanaan internal yang bisa mengurangi ketergantungan terhadap pendanaan eksternal yang seringkali mahal (Baños-Caballero et al., 2013 dalam Altaf dan Shah, 2018).

$\mathrm{H}_{1}$ : Cash conversion cycle berpengaruh negatif terhadap firm profitability

Piutang dapat dilihat sebagai pinjaman jangka pendek kepada customers yang diberikan oleh perusahaan pemasok yang akan dikembalikan dalam periode waktu tertentu (Martinez-Sola et al., 2013; Danielson \& Scott, 2004 dalam Altaf \& Shah, 2018). Accounts receivable period (ARP) atau accounts collection period (ACP) adalah periode waktu yang diperlukan untuk mengubah kembali piutang menjadi uang tunai atau untuk mengumpulkan uang tunai dari customers (Mathuva, 2010 dalam Altaf \& Shah, 2018). Perusahaan yang menanamkan piutang dalam jumlah yang besar memiliki risiko berupa bad debt (piutang tidak tertagih) dan opportunity cost (Murhadi, 2013). Secara umum, perusahaan yang semakin cepat mengumpulkan piutang-piutangnya akan berdampak baik bagi profitabilitas perusahaan. Karena dengan mempercepat periode pengumpulan piutang maka perusahaan dapat memutar uang yang diperoleh dari piutang tersebut ke berbagai investasi lainnya yang menguntungkan sehingga dapat meningkatkan profitabilitas perusahaan.

$\mathrm{H}_{2}$ : Accounts receivable conversion period berpengaruh negatif terhadap firm profitability

Persediaan merupakan barang yang dibeli dengan tujuan dijual kembali untuk mendapatkan keuntungan (Altaf \& Shah, 2018). Inventories conversion period (ICP) didefinisikan sebagai jangka waktu pada saat perusahaan membeli bahan baku, memproses bahan baku, hingga menjadi barang jadi yang dapat dijual ke pasar untuk menghasilkan keuntungan. Persediaan perusahaan tidak boleh terlalu sedikit dan tidak boleh terlalu banyak. Apabila perusahaan terlalu banyak menanamkan investasi dalam bentuk inventory maka akan meningkatkan opportunity cost yang nantinya 
akan membebani perusahaan (Murhadi, 2013). Pengelolaan inventory yang baik adalah mempercepat perputaran inventory dengan memproses lebih cepat mulai dari bahan baku hingga menjadi barang jadi dan barang tersebut dapat dijual ke pasar (Murhadi, 2013). Semakin pendek ICP, menunjukkan bahwa perusahaan dapat mengelola inventory dengan baik sehingga tidak membebani perusahaan dan perusahaan dapat menggunakan dananya untuk investasi lain yang lebih menguntungkan dan bisa meningkatkan profitabilitas perusahaan.

$\mathrm{H}_{3}$ : Inventories conversion period berpengaruh negatif terhadap firm profitability

Utang adalah salah satu sumber utama pendanaan eksternal jangka pendek tanpa jaminan untuk perusahaan (Wilner, 2000 dalam Altaf \& Shah, 2018). Accounts payable deferral period (APP) merupakan jangka waktu pada saat perusahaan melakukan transaksi secara kredit hingga perusahaan melunasi transaksi kredit itu (utang) secara tunai (menggunakan kas). APP memgukur berapa lama waktu yang dibutuhkan perusahaan untuk melunasi utangnya kepada supplier. Dengan memperlambat pembayaran utang maka perusahaan dapat memanfaatkan dana yang ada untuk keperluan lainnya atau bisa juga disimpan dalam bentuk investasi jangka pendek yang likuid sehingga dapat menghasilkan pemasukan bagi perusahaan (Murhadi, 2013). Semakin panjang APP dapat meningkatkan profitabilitas perusahaan karena menunda pembayaran ke suppliers akan mengurangi transactional costs dan exchange cost (Mathuva, 2010; Bhattacharya, 2008; Banerjee et al., 2007 dalam Altaf \& Shah, 2018).

$\mathrm{H}_{4}$ : Accounts payable deferral period berpengaruh positif terhadap firm profitability

\section{METODE PENELITIAN}

Penelitian ini termasuk dalam jenis basic research dimana penelitian ini bertujuan untuk mengembangkan penelitian yang telah dilakukan sebelumnya. Berdasarkan tujuannya, penelitian ini termasuk jenis penelitian kausal karena penelitian ini menguji pengaruh variabel independen, yaitu cash conversion cycle (CCC), accounts receivable conversion period (ACP), inventories conversion period (ICP), dan accounts payable deferral period (APP) terhadap variabel dependennya, yaitu firm profitability yang diukur dengan gross profit margin (GPM) pada perusahaan sektor manufaktur yang terdaftar di Bursa Efek Indonesia dan Bursa Efek Filipina periode 2014-2018. Dilihat dari pendekatannya, penelitian ini termasuk penelitian kuantitatif karena melibatkan data-data kuantitatif dalam menilai profitabilitas perusahaan.

Jenis data yang digunakan dalam penelitian ini adalah data kuantitatif yang melibatkan banyak waktu (time series) dengan banyak sampel (cross section) atau biasa disebut data panel. Data yang digunakan dalam penelitian ini adalah data sekunder berupa laporan keuangan seluruh perusahaan sektor manufaktur yang terdaftar di Bursa Efek Indonesia dan Bursa Efek Filipina periode 2014-2018. Prosedur pengumpulan data yang digunakan dalam penelitian ini adalah sebagai berikut: 
a. Menetapkan data-data yang diperlukan sesuai dengan variabel yang diukur dalam penelitian.

b. Mengunduh data laporan keuangan perusahaan dari website penyedia data, yaitu IDX (www.idx.co.id), PSE (www.pse.com.ph), dan website-website perusahaan.

c. Mengolah data mentah yang diperoleh dari website penyedia data sesuai dengan variabel-variabel yang digunakan dalam penelitian.

Penelitian ini menggunakan metode pengolahan data regresi linier berganda untuk mengetahui pengaruh variabel independen terhadap variabel dependen. Berdasarkan metode analisis dan hipotesis penelitian, variabel-variabel yang digunakan dalam penelitian ini dapat dibedakan menjadi satu variabel dependen (firm profitability), empat variabel independen (CCC, ACP, ICP, dan APP), serta dua variabel kontrol (leverage dan firm size). Penelitian ini menggunakan empat model regresiPersamaan yang digunakan dalam penelitian ini adalah sebagai berikut:

Model 1:

$G_{P P M_{i, t}}=\beta_{0}+\beta_{1} \cdot C C C_{i, t}+\beta_{2} . \operatorname{Lev}_{i, t}+\beta_{3}$. Size $_{i, t}+€$

Model 2:

$G P M_{i, t}=\beta_{0}+\beta_{1} \cdot A C P_{i, t}+\beta_{2} . L_{e v} v_{i, t}+\beta_{3}$. Size $_{i, t}+€$

Model 3:

$G P M_{i, t}=\beta_{0}+\beta_{1} \cdot I C P_{i, t}+\beta_{2} \cdot$ Lev $_{i, t}+\beta_{3}$. Size $_{i, t}+€$

Model 4:

$G P M_{i, t}=\beta_{0}+\beta_{1} \cdot A P P_{i, t}+\beta_{2} \cdot$ Lev $_{i, t}+\beta_{3}$. Size $_{i, t}+€$

Keterangan:

$\mathrm{GPM}_{\mathrm{i}, \mathrm{t}} \quad=$ Gross profit margin perusahaan i pada periode ke $\mathrm{t}$

$\mathrm{CCC}_{\mathrm{i}, \mathrm{t}} \quad=$ Cash conversion cycle perusahaan i pada periode ke $\mathrm{t}$

$\mathrm{ACP}_{\mathrm{i}, \mathrm{t}} \quad=$ Accounts receivable conversion period perusahaan i pada periode ke $\mathrm{t}$

$\mathrm{ICP}_{\mathrm{i}, \mathrm{t}} \quad=$ Inventories conversion period perusahaan i pada periode ke $\mathrm{t}$

$\mathrm{APP}_{\mathrm{i}, \mathrm{t}} \quad=$ Accounts payable deferral period perusahaan i pada periode ke $\mathrm{t}$

$\mathrm{Lev}_{\mathrm{i}, \mathrm{t}}=$ Leverage perusahaan i pada periode $\mathrm{ke} \mathrm{t}$

Size $_{\mathrm{i}, \mathrm{t}} \quad=$ Size perusahaan i pada periode ke $\mathrm{t}$

\section{RESULTS \& DISCUSSION}

Penelitian ini menggunakan sampel perusahaan manufaktur yang terdaftar di Bursa Efek Indonesia dan Bursa Efek Filipina periode 2014-2018 dan sampel akhir terdiri dari 625 observasi untuk sampel Indonesia dan 205 observasi untuk sampel Filipina. Statistik Deskriptif ditunjukkan dalam tabel 1 untuk sampel Indonesia dan tabel 2 untuk sampel Filipina. 


\section{Tabel 1.}

Statistik Deskriptif Sampel Indonesia

\begin{tabular}{|l|c|c|c|c|c|c|c|}
\hline & GPM & CCC & ACP & ICP & APP & LEV & SIZE \\
\hline Mean & 0.175904 & 117.0802 & 59.89070 & 111.4376 & 54.24816 & 0.536113 & 28.51546 \\
\hline Median & 0.175149 & 96.52532 & 51.42235 & 85.13727 & 46.96395 & 0.484454 & 28.33647 \\
\hline Maximum & 0.738795 & 662.8556 & 375.0432 & 654.4024 & 374.2812 & 5.073297 & 33.47373 \\
\hline Minimum & -15.77801 & -108.6793 & 3.457391 & 3.410879 & 0.656460 & 0.050103 & 25.21557 \\
\hline Std. Dev. & 0.659608 & 96.96591 & 38.94797 & 81.86134 & 40.16455 & 0.491667 & 1.568605 \\
\hline Skewness & -22.68040 & 1.495946 & 2.215233 & 2.360404 & 2.271251 & 6.100343 & 0.567786 \\
\hline Kurtosis & 549.3542 & 6.816700 & 12.46830 & 12.03574 & 13.40388 & 51.93713 & 3.073211 \\
\hline & & & & & & & \\
\hline Jarque-Bera & 7827097. & 612.4638 & 2845.773 & 2706.525 & 3356.122 & 66242.17 & 33.72095 \\
\hline Probability & 0.000000 & 0.000000 & 0.000000 & 0.000000 & 0.000000 & 0.000000 & 0.000000 \\
\hline & & & & & & & \\
\hline Sum & 109.9399 & 73175.10 & 37431.69 & 69648.51 & 33905.10 & 335.0709 & 17822.17 \\
\hline $\begin{array}{l}\text { Sum Sq. } \\
\text { Dev. }\end{array}$ & 271.4915 & 5867090. & 946573.4 & 4181598. & 1006631. & 150.8433 & 1535.366 \\
\hline & & & & & & & \\
\hline Observations & 625 & 625 & 625 & 625 & 625 & 625 & 625 \\
\hline
\end{tabular}

Tabel 2.

Statistik Deskriptif Sampel Filipina

\begin{tabular}{|l|c|c|c|c|c|c|c|}
\hline & GPM & CCC & ACP & ICP & APP & LEV & SIZE \\
\hline Mean & 0.226802 & 56.52091 & 65.45225 & 72.84430 & 81.77565 & 0.514363 & 29.32972 \\
\hline Median & 0.212902 & 48.16136 & 52.37113 & 51.43116 & 51.99400 & 0.533655 & 29.24301 \\
\hline Maximum & 0.650328 & 417.9551 & 393.4674 & 584.9699 & 896.8783 & 1.191707 & 32.31994 \\
\hline Minimum & -0.207522 & -226.1804 & 6.912385 & 1.817681 & 3.201053 & 0.084052 & 24.47287 \\
\hline Std. Dev. & 0.129326 & 109.0292 & 58.55639 & 82.28687 & 125.5916 & 0.185634 & 1.601789 \\
\hline Skewness & 0.427315 & 0.423493 & 2.617189 & 3.522354 & 5.100674 & 0.062169 & -0.179536 \\
\hline Kurtosis & 4.207656 & 4.718456 & 11.85506 & 19.03216 & 31.45256 & 3.367336 & 3.481587 \\
\hline & & & & & & & \\
\hline Jarque-Bera & 18.69623 & 31.35198 & 903.7999 & 2619.370 & 7803.802 & 1.284628 & 3.082331 \\
\hline Probability & 0.000087 & 0.000000 & 0.000000 & 0.000000 & 0.000000 & 0.526074 & 0.214131 \\
\hline & & & & & & & \\
\hline Sum & 46.49432 & 11586.79 & 13417.71 & 14933.08 & 16764.01 & 105.4445 & 6012.593 \\
\hline $\begin{array}{l}\text { Sum Sq. } \\
\text { Dev. }\end{array}$ & 3.411946 & 2425024. & 699485.6 & 1381310. & 3217744. & 7.029810 & 523.4082 \\
\hline & & & & & & & \\
\hline Observations & 205 & 205 & 205 & 205 & 205 & 205 & 205 \\
\hline
\end{tabular}

Dari tabel 1 terlihat bahwa rata-rata Gross Profit Margin perusahaan mencapai 18\% dengan rata-rata cash conversion cycle 117 hari, accounts receivable conversion period 60 hari, inventories conversion period 111 hari, dan accounts payable deferral period 54 hari. Sedangkan rata-rata leverage perusahaan sebesar 
54\% dan size perusahaan sebesar 29\%. Dari tabel 2 terlihat bahwa rata-rata Gross Profit Margin perusahaan mencapai 23\% dengan rata-rata cash conversion cycle 57 hari, accounts receivable conversion period 65 hari, inventories conversion period 73 hari, dan accounts payable deferral period 82 hari. Sedangkan rata-rata leverage perusahaan sebesar 51\% dan size perusahaan sebesar 29\%. Setelah memperhatikan statistik deskriptif di atas, maka dilakukan uji asumsi klasik, dimana keempat model yang digunakan lolos terhadap uji multikolinearitas, autokorelasi, dan heteroskedastisitas.

Tabel 3.

Hasil Uji Regresi Sampel Indonesia

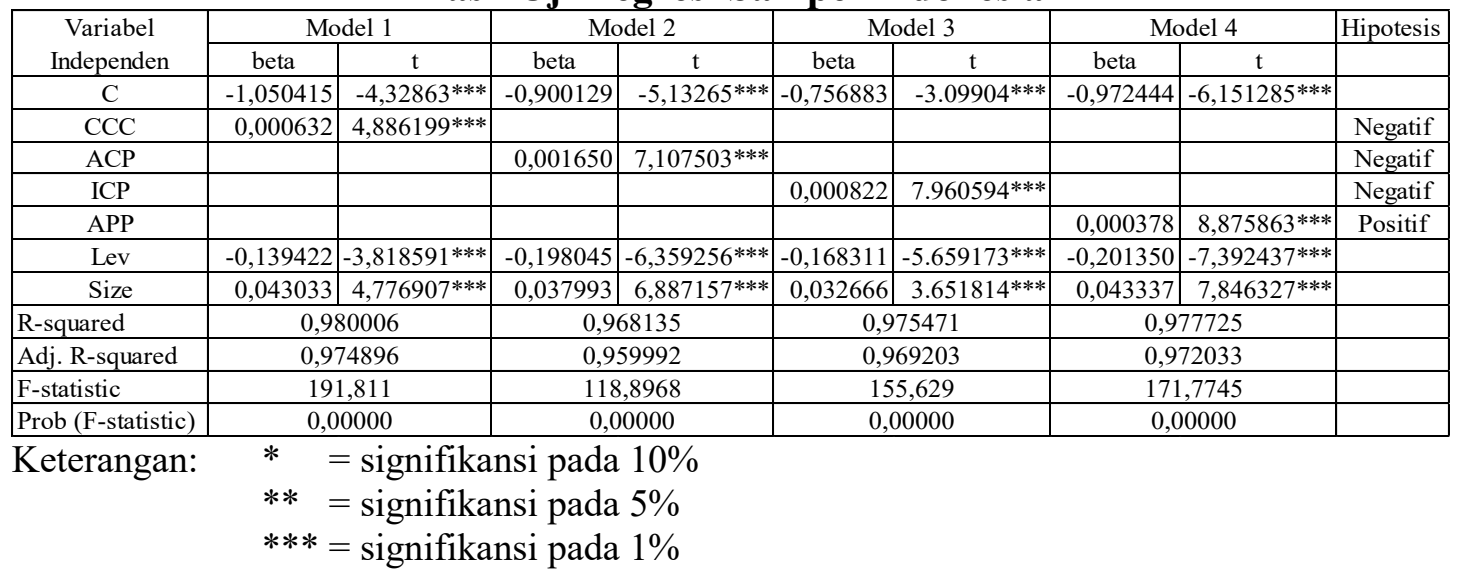

Pada tabel 3 dilakukan uji regresi sampel Indonesia model 1, model 2, model 3, dan model 4. Hasil uji regresi model 1 menunjukkan bahwa CCC berpengaruh positif signifikan terhadap profitabilitas perusahaan. Hal ini bermakna semakin panjang CCC maka profitabilitas perusahaan akan meningkat karena CCC yang panjang dapat menstimulasi penjualan, memberikan customer waktu untuk membedabedakan produk, mengurangi information asymmetry antara pembeli dan penjual, mencegah interupsi produksi, dan memperkuat hubungan jangka panjang antara supplier dengan customer (Deloof, 2003; Deloof \& Jegers, 1996; Smith, 1987; Ng, et al., 1999; Wilner, 2000 dalam Altah \& Shah, 2018).

Hasil uji regresi model 2 menunjukkan bahwa ACP berpengaruh positif signifikan terhadap profitabilitas perusahaan. Hal ini bermakna semakin panjang ACP maka profitabilitas perusahaan akan meningkat. Perusahaan yang memiliki kebijakan piutang agresif (aggressive receivables policy) akan menghasilkan pengurangan periode piutang yang akan meningkatkan ketersediaan uang tunai bagi perusahaan. Sedangkan perusahaan yang memiliki kebijakan piutang konservatif (conservative receivables policy) akan menghasilkan peningkatan periode piutang yang akan meningkatkan investasi dalam modal kerja. Semakin panjang periode penagihan piutang akan meningkatkan investasi pada working capital, memberi customer waktu untuk memverifikasi kualitas produk sebelum membayar (Altaf \& Shah, 2018). 
Selain itu, memperpanjang periode penagihan piutang juga dapat mengurangi terjadinya information asymmetry antara pembeli dan penjual (Smith, 1987 dalam Altaf \& Shah (2018). Deloof \& Jegers (1996) dalam Abuzayed (2012) menyatakan perusahaan dengan profit/laba yang lebih tinggi memiliki lebih banyak uang tunai untuk dipinjamkan kepada pelanggan. Jadi dengan melonggarkan kebijakan penagihan piutang, perusahaan dapat meningkatkan profitabilitas karena penjualan juga akan meningkat. Hal ini juga dapat digunakan sebagai strategi bersaing terhadap kompetitor-kompetitor perusahaan. Namun, perusahaan juga harus memastikan bahwa dengan memperpanjang periode penagihan piutang, maka juga harus didukung dengan peningkatan penjualan agar profitabilitas meningkat. Selain itu, perusahaan juga harus mempertimbangkan risiko bad debt (piutang tak tertagih) dalam menerapkan kebijakan piutangnya.

Hasil uji regresi model 3 menunjukkan bahwa ICP berpengaruh positif signifikan terhadap profitabilitas perusahaan. Hal ini bermakna semakin panjang ICP maka profitabilitas perusahaan akan meningkat. Perusahaan dengan kebijakan manajemen persediaan agresif (aggressive inventory management policy) mempertahankan investasi yang lebih rendah dalam persediaan, sehingga menghindari biaya penyimpanan persediaan, usang, asuransi, dan lain-lain. Sedangkan perusahaan dengan kebijakan manajemen persediaan konservatif (conservative inventory management policy) akan membantu perusahaan untuk memenuhi semua permintaan di pasar tetapi mempertahankan investasi yang lebih tinggi membuat perusahaan menghadapi sejumlah biaya. Perusahaan yang menganut kebijakan manajemen persediaan konservatif (conservative inventory management policy) dengan melakukan investasi tambahan dalam persediaan dapat menstimulasi profitabilitas dengan meningkatkan penjualan (Deloof 2003, dalam Altaf \& Shah, 2018). Namun, perusahaan harus memastikan bahwa barang akan laku terjual sehingga menghasilkan pemasukan bagi perusahaan ketika memutuskan untuk menambah investasi pada persediaan. Jangan sampai perusahaan terlalu menyimpan persediaan karena akan menimbulkan biaya-biaya yang dapat mengurangi profitabilitas perusahaan. Oleh karena itu, dalam praktiknya, perusahaan dalam menentukan kebijakan manajemen persediannya harus mempertimbangkan antara costs dan benefits yang akan diterima perusahaan.

Hasil uji regresi model 4 menunjukkan bahwa APP berpengaruh positif signifikan terhadap profitabilitas perusahaan. Hal ini bermakna semakin panjang APP maka profitabilitas perusahaan akan meningkat. Hasil penelitian ini logis karena semakin panjang periode pembayaran utang dapat membantu perusahaan meningkatkan profitabilitas dengan menunda pembayaran ke supplier sehingga mengurangi transactional cost dan exchange cost, dan membantu perusahaan mengontrol dan mengelola kualitas barang yang dibeli sehingga mengurangi information asymmetry antara pembeli dan penjual (Mathuva, 2010; Bhattacharya, 2008; Banerjee et al., 2007; Raheman et al., 2010; Pike, et al., 2005; Smith, 1987 dalam Altaf dan Shah 2018). Selain itu, dengan memperlambat pembayaran utang maka perusahaan dapat memanfaatkan dana yang ada untuk keperluan lainnya 
ataupun dapat disimpan dalam investasi jangka pendek yang bersifat likuid sehingga akan mendatangkan pemasukan bagi perusahaan (Murhadi, 2013).

Tabel 4.

Hasil Uji Regresi Sampel Filipina

\begin{tabular}{|c|c|c|c|c|c|c|c|c|c|}
\hline \multirow{2}{*}{$\begin{array}{c}\text { Variabel } \\
\text { Independen }\end{array}$} & \multicolumn{2}{|c|}{ Model 1} & \multicolumn{2}{|c|}{ Model 2} & \multicolumn{2}{|c|}{ Model 3} & \multicolumn{2}{|c|}{ Model 4} & \multirow[t]{2}{*}{ Hipotesis } \\
\hline & beta & $\mathrm{t}$ & beta & $\mathrm{t}$ & beta & $\mathrm{t}$ & beta & $\mathrm{t}$ & \\
\hline $\mathrm{C}$ & $-0,487253$ & $-1,852453 *$ & $-0,471625$ & $-1,800518^{*}$ & $-0,489750$ & $-1,868631 *$ & $-0,482538$ & $-1,838194 *$ & \\
\hline $\mathrm{CCC}$ & 0,0000577 & 0,787777 & & & & & & & Negatif \\
\hline ICP & & & & & 0,000104 & 1,094833 & & & Negatif \\
\hline APP & & & & & & & $-0,0000577$ & $-0,689266$ & Positif \\
\hline R-squared & \multicolumn{2}{|c|}{0,096252} & \multicolumn{2}{|c|}{0,099439} & \multicolumn{2}{|c|}{0,09867} & \multicolumn{2}{|c|}{0,096139} & \\
\hline Adj. R-squared & \multicolumn{2}{|c|}{0,082763} & \multicolumn{2}{|c|}{0,085997} & \multicolumn{2}{|c|}{0,085217} & \multicolumn{2}{|c|}{0,082649} & \\
\hline F-statistic & \multicolumn{2}{|c|}{7,135698} & \multicolumn{2}{|c|}{7,398042} & \multicolumn{2}{|c|}{7,334586} & \multicolumn{2}{|c|}{7,126459} & \\
\hline Prob (F-statistic) & \multicolumn{2}{|c|}{0,000141} & \multicolumn{2}{|c|}{0,0001} & \multicolumn{2}{|c|}{0,000109} & \multicolumn{2}{|c|}{0,000142} & \\
\hline
\end{tabular}

Keterangan: $\quad * \quad=$ signifikansi pada $10 \%$

$* *$ = signifikansi pada $5 \%$

$* * *=$ signifikansi pada $1 \%$

Pada tabel 4 dilakukan uji regresi sampel Filipina model 1, model 2, model 3, dan model 4. Hasil penelitian menunjukkan bahwa CCC, ACP, ICP, dan APP tidak memiliki pengaruh yang signifikan terhadap profitabilitas perusahaan. Hal ini bermakna CCC, ACP, ICP, dan APP tidak berpengaruh terhadap profitabilitas perusahaan di Filipina. Hasil ini menunjukkan bahwa meskipun perusahaan telah melakukan manajemen modal kerjanya dengan baik, namun tidak mempengaruhi keputusan customer maupun supplier. Jadi, ada faktor lain di luar modal kerja yang menjadi pertimbangan customer dan supplier dalam aktivitas operasi perusahaanperusahaan manufaktur di Filipina. Menurut Abuzayed (2012) hal ini mungkin disebabkan karena rendahnya transparansi tentang kinerja perusahaan yang mempengaruhi keputusan investor. Dengan demikian investor memiliki keterbatasan dalam hal memahami kinerja keuangan yang diukur menggunakan accounting profitability (gross profit margin). Selain itu, investor juga memiliki keterbatasan dalam memahami seberapa tinggi telah terjadi pertumbuhan dalam perputaran manajemen modal kerja. Oleh karena itu, dirasa penting untuk melengkapi pengukuran kinerja perusahaan menggunakan basis market performance dengan harapan bisa memberikan hasil pengujian yang lebih baik.

Hasil penelitian untuk variabel leverage menunjukkan bahwa leverage berpengaruh negatif signifikan terhadap profitabilitas perusahaan di Indonesia dan Filipina. Hasil ini menunjukkan bahwa semakin kecil leverage perusahaan, bearti perusahaan tersebut mampu mengoptimalkan pendanaan internalnya dan tidak terlalu bergantung terhadap pendanaan eksternal untuk menjalankan kegiatan operasionalnya sehingga dapat memaksimalkan profit. Sebaliknya, semakin tinggi leverage perusahaan akan mendorong beban bunga yang besar serta kemungkinan kebangkrutan yang lebih besar daripada manfaat penghematan pajak (tax saving), 
sehingga mengakibatkan profit perusahaan akan menurun. Oleh karena itu, lebih baik bagi perusahaan untuk sebisa mungkin memanfaatkan pendanaan internalnya untuk melakukan aktivitas operasional untuk mengurangi risiko perusahaan mengalami financial distress. Sedangkan hasil penelitian untuk variabel size menunjukkan bahwa size berpengaruh positif signifikan terhadap profitabilitas perusahaan di Indonesia dan Filipina. Hal ini bermakna semakin besar ukuran perusahaan maka perusahaan akan mencapai skala ekonomis sehingga profitabilitas perusahaan juga akan meningkat (Murhadi, 2013). Selain itu, perusahaan berskala kecil cenderung kurang menguntungkan apabila dibandingkan dengan perusahaan yang berskala besar (Francis, 1986; Grubber dan Elton, 1995; serta Fama dan French, 1995 dalam Ibrahim, 2008). Jadi, semakin besar ukuran perusahaan, maka perusahaan bisa memproduksi barang dalam jumlah besar sekaligus sehingga dapat mencapai skala ekonomis yang dapat meningkatkan profitabilitas perusahaan.

\section{KONKLUSI}

Dari pembahasan di atas, dapat disimpulkan bahwa CCC, ACP, ICP, dan APP memiliki pengaruh positif signifikan terhadap profitabilitas perusahaan di Indonesia. Hal ini bermakna semakin panjang $\mathrm{CCC}$, ACP, ICP, dan APP perusahaan maka profitabilitas perusahaan akan meningkat. Dari hasil ini dapat disimpulkan bahwa sebagian besar perusahaan manufaktur di Bursa Efek Indonesia menerapkan kebijakan modal kerja konservatif (conservative working capital policy). Untuk sampel Filipina, hasil tidak signifikan CCC, ACP, ICP, dan APP menunjukkan bahwa CCC, ACP, ICP, dan APP tidak berpengaruh terhadap profitabilitas perusahaan manufaktur di Bursa Efek Filipina. Hasil ini menunjukkan bahwa meskipun perusahaan telah melakukan manajemen modal kerjanya dengan baik, namun tidak mempengaruhi keputusan customer maupun supplier. Jadi, ada faktor lain di luar modal kerja yang menjadi pertimbangan customer dan supplier dalam aktivitas operasi perusahaan-perusahaan manufaktur di Filipina. Selain itu, hal ini juga disebabkan rendahnya transparansi perusahaan terkait kinerja perusahaan sehingga hal ini akan mempengaruhi keputusan investasi para investor. Oleh karena itu, dirasa penting untuk melengkapi pengukuran kinerja perusahaan menggunakan basis market performance.

Penelitian ini dapat dijadikan referensi untuk penelitian-penelitian selanjutnya. Penelitian ini memiliki keterbatasan dalam hal periode penelitian, obyek penelitian, serta variabel yang digunakan. Oleh karena itu, diharapkan peneliti selanjutnya dapat menambah periode penelitian, obyek penelitian, serta variabelvariabel relevan lainnya yang belum digunakan dalam penelitian ini. 


\section{DAFTAR PUSTAKA}

Abuzayed, B. (2012). Working capital management and firms' performance in emerging markets: the case of Jordan. International Journal of Managerial Finance, 8(2), 155-179.

Afrifa, G.A. \& Padachi K. (2016). Working capital level influence on SME profitability. Journal of Small Business and Enterprise Development, 23(1), 4463.

Altaf, N, \& Shah, FA. (2018). How does working capital management affect the profitability of Indian companies? Journal of Advances in Management Research, 15(3), 347-266.

Banerjee, S., Gatchev, V.A. \& Spindt, P.A. (2007). Stock market liquidity and firm dividend policy. Journal of Financial and Quantitative Analysis, 42(2), 369397.

Baños-Caballero, S., García-Teruel, P.J. \& Martínez-Solano, P. (2013). The speed of adjustment in working capital requirement. The European Journal of Finance, 19(10), 978-992.

Danielson, M.G. \& Scott, J.A. (2004). Bank loan availability and trade credit demand. Financial Review, 39(4), 579-600.

Deloof, M, \& Jegers, M. (1996). Trade credit, product quality, and intragroup trade: some European evidence. Financial Management, 25(3), 33-43.

Deloof, M. (2003). Does Working Capital Management Affect Profitability of Belgian Firms. Journal of Business Funance and Accounting, 30(3\&4), 573587.

Ibrahim, H. (2008). Pengaruh Tingkat Suku Bunga, Peringkat Obligasi, Ukuran Perusahaan dan DER terhadap Yield to Maturity Obligasi Korporasi di Bursa Efek Indoneia Periode Tahun 2004-2006 [Tesis]. Semarang: Universitas Diponegoro.

Martínez-Sola, C., García-Teruel, P.J. \& Martínez-Solano, P. (2013). Corporate cash holding and firm value. Applied Economics, 45(2), 161-170.

Mathuva, D. (2010). The influence of working capital management components on corporate profitability: a survey on Kenyan listed firms. Research Journal of Business Management, 4(1): 1-11.

Murhadi, W.R. (2013). Manajemen Modal Kerja dan Profitabilitas di Bursa Efek Indonesia. Pontianak: Proceedings FMI Universitas Tanjung Pura.

Ng, C.K., Smith, J.K. \& Smith, R.L. (1999). Evidence on the determinants of credit terms used in interfirm trade. The Journal of Finance, 54(3): 1109-1129.

Padachi, K. (2006). Trends in working capital management and its impact on firms' performance: an analysis of Mauritian small manufacturing firms. International Review of Business Research Papers, 2(2): 45-58.

Pais, M.A. \& Gama, P.M. (2015). Working capital management and SMEs profitability: Portuguese evidence. International Journal of Managerial Finance, 11(3): 341-358. 
Pike, R., Cheng, N.S., Cravens, K. \& Lamminmaki, D. (2005). Trade credit terms: asymmetric information and price discrimination evidence from three continents. Journal of Business Finance \& Accounting, 32(5\&6), 1197-1236.

Raheman, A., Afza, T., Qayyum, A. \& Bodla, M.A. (2010). Working capital management and corporate performance of manufacturing sector in Pakistan. International Research Journal of Finance and Economics, 47(1), 156-169.

Shin, H.H. \& Soenen, L. (1998). Efficiency of Working Capital and Corporation Profitability. Financial Practice and Education: Journal of the Financial Management Association, 8(2), 37-45.

Smith, J.K. (1987). Trade credit and informational asymmetry. The Journal of Finance, 42(4), 863-872.

Smith, K. (1980). Profitability versus liquidity tradeoffs in working capital management. Readings on the Management of Working Capital, 42, 549-562.

Syaifuddin, D.T. (2008). Manajemen Keuangan (Teori dan Aplikasi). Kendari: Unhalu Press.

Tahir, M. \& Anuar. (2016). The determinants of working capital management and firms performance of textile sector in Pakistan. Quality \& Quantity, 50(2), 605618.

Tauringana, V. \& Afrifa, G.A. (2013). The relative importance of working capital management and its components to SMEs profitability. Journal of Small Business and Enterprise Development, 20(3), 453-469.

Tran, H., Abbott, M. \& Yap, C.J. (2017). How does Working Capital Management Affect the Profitability of Vietnamese Small and Medium Sized Enterprises?. Journal of Small Business and Enterprise Development, 24(1), 2-11.

Wilner, B.S. (2000). The exploitation of relationships in financial distress: The case of trade credit. The Journal of Finance, 55(1), 153-178. 